\title{
Sobre o Risco Necessário de Apostar no Futuro
}

\section{On the Necessary Risk of Trusting in the Future}

\author{
Antenor Amâncio-Filho ${ }^{1}$
}

\begin{abstract}
AMÂNCIO-FILHO, A. On the Necessary Risk of Trusting in the Future. Cad. Saúde Públ., Rio de Faneiro, 10 (4): 505-507, Oct/Dec, 1994.

As the result of its centralized, exclusive economic model, Brazil has undergone a serious economic, political, and social crisis. The crisis is getting worse because the country is simultaneously undergoing extensive demographic, epidemiological, and technological changes. There is an urgent need to articulate various social groups to challenge and change the ongoing situation. A new historical future has to be established so that a different and less unequal society can emerge and guarantee better living conditions for coming generations.
\end{abstract}

Key words:Demography; Epidemiology; Technology; Transition; Modernity

Observa-se no Brasil peculiar e crucial momento de grave crise, que conjuga dimensões econômicas, políticas e sociais. Talvez como em nenhum outro período da história do país, a virulência dessa crise vem agravando e fazendo aflorar uma série de contradições, grande parte delas produto de uma sociedade que se caracteriza pelo modo perverso com que estimula e favorece o crescimento de um largo contingente populacional de despossuídos. Despossuídos de educação, de saúde, de moradia, de alimentação, de mínimas condições de sobrevivência.

No bojo dessa crise sem precedentes, cuja abrangência transforma o cotidiano da sociedade, vista como um todo, em alarmante situação de permanente instabilidade, se inserem determinadas questões cujo enfrentamento faz-se urgente e inadiável, sob o risco de agravamento do quadro nacional. Nesse contexto, nos defrontamos ainda com os chamados processos de transição epidemiológica, demográfica e tecnológica, que reforçam e alimentam a difícil e dolorosa travessia pela qual passa nossa sociedade.

Esse conjunto de movimentos, que se interligam, se interdependem em um real momento de

${ }^{1}$ Escola Politécnica de Saúde Foaquim Venâncio da Fundação Oswaldo Cruz. Avenida Brasil, 4036, sala 201, Rio de Faneiro, RF, 21040-361, Brasil. "purgação histórica", permite avaliar a complexidade e profundidade dos problemas que nos envolvem e que necessitam serem enfrentados de maneira competente e vigorosa para que seja mantido o sonho de se construir uma sociedade diferente da atual.

Os processos de transição acima apontados (epidemiológico, demográfico e tecnológico) se instalaram sobretudo em virtude de um modelo econômico excludente e perverso, que os gerou e os alimenta. No entanto, não basta identificar causas, é preciso mais que nunca buscar alternativas para a superação de suas conseqüências. É preciso clarificá-las e procurar soluções que sejam as menos traumáticas para o conjunto da sociedade.

A transição demográfica pode ser caracterizada pela cojugação de dois fatores: redução das taxas de mortalidade infantil, possibilitando, em decorrência, aumento significativo da população nessa faixa etária e um aumento considerável da expectativa de vida da população, com ampliação crescente do contingente de idosos. Essa mudança do perfil populacional se por um lado atesta uma importante alteração nas condições de saúde da população, por outro implica na necessidade do segmento populacional economicamente ativo ampliar o esforço no sentido de gerar mais recursos para manter um universo maior de pessoas. Acresce a essa circunstância o modelo econômico vigente, extremamente concentrador de renda, que 
obriga um largo segmento da sociedade a sobreviver excluído do mercado de trabalho, favorecendo ainda a permanência de milhões de brasileiros em situação de miséria absoluta. A transição demográfica amplia o desafio de gerar mais empregos, de redimensionar os setores da educação, da saúde, dos transportes, da habitação, no sentido de buscar alternativas que apontem para a redução das carências que afligem nossa população.

A transição epidemiológica reside nos extremos contrastes sanitários produzidos pela sociedade brasileira. Enquanto grande parcela da população convive e procura resistir a doenças e males prevalentes no início do século (malária, cólera, tuberculose, dengue), outro segmento menor e privilegiado dispõe, por exemplo, das mais avançadas técnicas médicas e sofisticados equipamentos, como tomógrafo computadorizado, unidades móveis de atendimento e acesso a modernas técnicas de transplante.

O terrível contraste entre a maioria dos que nada possuem em termos de acesso a condições básicas de saúde e uma minoria que usufrui do que existe de mais moderno em termos de tecnologia médica, se insere no conjunto de fatores que caracterizam uma transição epidemiológica que alia males "arcaicos" com novos e crescentes agravos à integridade física e psíquica do homem, como as doenças cardiovasculares, os acidentes de trânsito, a violência urbana, o stress emocional, a Aids. Essa transição nos compele a repensar nosso papel frente a urgente necessidade de estabelecer mecanismos que possibilitem uma crescente cobertura preventiva e assistencial à população, buscando erradicar as velhas doenças mediante a implementação de políticas sociais conseqüentes $\mathrm{e}$ comprometidas com os interesses da maioria e criando condições, para o conjunto da população, como rotina incorporada, de acesso ao que existe de mais civilizado para a preservação e manutenção da vida. Vencer essa transição epidemiológica é abraçar o desafio de reduzir a histórica distância que separa uma minoria que usufrui de todos os privilégios de uma esmagadora maioria de despossuídos.

$\mathrm{O}$ que vem-se constituindo em uma transição tecnológica diz respeito ao fantástico desenvolvimento do conhecimento científico e técnico alcançado pelo homem nas últimas décadas e cujos resultados apontam para a premência de um repensar sobre a necessidade de ética na regulação do poder técnico e no direcionamento do crescimento econômico. Segundo Buarque (1994) isto representa " $a$ formulação e aceitação de uma ética que subordine o avanço técnico a novos processos civilizatórios, nos quais estejam refletidos o direito à liberdade de cada homem e a responsabilidade de cada um deles para participar da construção de uma civilização onde o equilíbrio ecológico seja garantido, onde nenhum ser humano seja excluído do mínimo necessário para a vida livre e criativa e onde o processo civilizatório tenha por objetivo o constante enriquecimento da humanidade em seus valores culturais". É, portanto, assumir o grande desafio de construir uma modernidade subordinada à ética e não tornando-a submissa escrava da técnica. Desafio que certamente implicará não um processo gradativo de mudança, mas na coragem de optar pela ruptura, no sentido de fazer a tecnologia condicionada aos interesses sociais. Esta a base para repensar uma ética que vise a melhoria de qualidade de vida do homem, onde a tecnologia seja olhada não como um fim ao qual o homem deve estar subordinado, mas como instrumento, "como meio de um projeto libertário" (Buarque, 1994).

Os pontos abordados representam uma parcela da gama de interrogações e desafios que se colocam no limiar de um novo século. Exigem de todos e de cada um grande esforço no sentido de buscar novos conhecimentos e diferentes formas de atuação, aliando um vigoroso impulso na exploração de nossa criatividade e um zelo contínuo para que as mutações que se processem não venham a colocar em risco as condições para a continuidade da espécie humana.

É preciso, por exemplo, implementar um urgente e rigoroso trabalho orientado para a análise e a proposição de medidas alternativas para enfrentar novas e velhas questões que se apresentam para o homem, contribuindo para a adoção de ações estratégicas que favoreçam o desenvolvimento sustentável, sem agressões ao meio ambiente.

É fundamental que o homem adote uma postura de modéstia diante da natureza, para 
que melhor possa avaliar o quanto a opção por determinado modelo econômico ameaça setores fundamentais da vida sobre a Terra. $\mathrm{O}$ avanço do processo civilizatório não pode conter em si o risco da extinção/anulação do homem, mas sim a possibilidade de um convívio social livre de amarras e opressões. É preciso aprofundar a reflexão sobre $o$ assunto, a fim de que se evite uma possível tragédia ecológica, alcançando "uma consciência exata dos riscos (e) uma nova formulação da teoria do valor que inclua a natureza em uma visão na qual um novo antropocentrismo entenda equilíbrio ecológico como necessário ao projeto humano" (Buarque, 1994). O compromisso em preservar e ampliar o patrimônio, o acervo natural onde o homem se situa, é o legado que nos cabe defender para garantir a existência das gerações futuras.

Se dificuldades se interpõem na construção de um mundo diferente, tais obstáculos devem nutrir e não fazer esquecer o sonho. Sonho que consiste em romper com a incompatibilidade entre a estrutura econômica e as necessidades e valores culturais da população; sonho que reside na visão global dos problemas do país e no conhecimento dos limites para as soluções; sonho que repousa na correta apreensão do real para buscar erguer um novo possível histórico.

Se hoje nos encontramos submersos em uma aguda crise de caráter político, econômico e social e, no interior dela, nos defrontamos com transições (como a demográfica, a epidemiológica e a tecnológica) que a aprofundam, esse panorama aparentemente desalentado deve se constituir em incentivo para o desafio de formular idéias sobre o tipo de país que a sociedade deseja. Desafio que impõe a necessidade de abandonar a retórica do desejo e assumir engajados na luta para a construção do tempo futuro - a prática de ações cotidianas que resultem em contribuição para que o país encontre o seu próprio caminho para a modernidade. O país de crises, de contrastes, de contradições, de misérias flagrantes e riqueza concentrada, possibilita a cada um de nós a aventura e o risco de ousar repensá-lo em bases diferentes das atuais, tendo como horizonte uma sociedade menos desigual, mais justa e solidária.

\section{RESUMO}

\section{AMÂNCIO-FILHO, A. Sobre o Risco Necessário de Apostar no Futuro. Cad.} Saúde Públ., Rio de Janeiro, 10 (4): 505-507, out/dez, 1994.

O Brasil atravessa momento de grave crise econômica, política e social, resultado, basicamente, de um modelo econômico centralizador e excludente. A crise se agrava na medida em que o país enfrenta, de modo simultâneo, transições demográficas, epidemiológica e tecnológica, tornando urgente e necessário o esforço conjunto e articulado dos diversos segmentos sociais no sentido de enfrentar o desafio de alterar o panorama existente, construindo um novo possível histórico, tendo por horizonte uma sociedade diferente da atual, menos desigual, mais justa e solidária, para garantir a existência das gerações futuras.

Palavras-Chave: Demografia; Epidemiologia; Tecnologia; Transição; Modernidade

\section{REFERÊNCIAS BIBLIOGRÁFICAS}

BUARQUE, C., 1994. A Aventura da Universidade. São Paulo: Unesp. 